\title{
Saccharin and sucrose intake in rats: Long- and short-term tests'
}

LOIS REEL HAMMER

THE GEORGE WASHINGTON UNIVERSITY

Twenty-four-hour and 30-min intake of sucrose and saccharin solutions were compared across a range of concentrations. While quantities ingested differed, the intake functions for each substance were similar over long and short periods. However, saccharin intake was markedly lower than sucrose over $24 \mathrm{~h}$, despite the absence of the satiating effects attributed to sucrose. It is suggested that qualitative taste differences rather than postingestional effects could account for differences in sucrose and saccharin preference.

Since Sheffield \& Roby's (1950) demonstrations that saccharin can be an effective reinforcer for rat behavior, saccharin has been rather widely used in studies of reinforcement, usually under the assumption that it acts simply as a noncaloric sugar in motivating behavior. Some recently noted inconsistencies in the acceptance of saccharin cast doubt on this assumption and raise other questions about its longer-term effects as well as its immediate reinforcement value (Capretta, 1962, 1964; Collier, 1962; Young \& Madsen, 1963). There is a need for more systematic data directly comparing sugar with saccharin across a wide range of concentrations. The present paper helps fill this need with observations on sucrose and saccharin intake by nondeprived rats, over short and long periods.

Some apparent contradictions have arisen when different preference measures were used. For example, level of intake is generally a poor index of reinforcement value for instrumental (nonconsummatory) behavior. While the initiation of eating may be a function of taste or palatability, the cessation of eating is controlled largely by gastric or postingestion factors. Thus for hypertonic sugar concentrations satiation interacts with palatability to yield a decline in intake as concentration increases, even for short test periods. This result is in direct contrast to the finding that immediate reinforcement value is directly related to sweetness when postingestion effects are minimized or equated (Guttman, 1954; Hammer, 1965). Under sham feeding, of which saccharin drinking could be considered an example, intake should correspond more closely to palatability as determined by other methods, since the inhibiting effect of stomach load is absent (Mook, 1963).

Procedure

Naive, male albino rats (Charles River CD strain), about $\mathbf{1 0 0}$ days old at the start of the experiment, were housed in standard, individual cages. All testing was carried out in the home cages. An artificial day/night cycle was maintained in the test room. The animals were kept on ad lib food and water throughout the experiment.
Six rats recelved sucrose only, six received saccharin. Each concentration in the test series was presented to each $S$ for four days at a time. Each $S$ in a group received all concentrations in a different, counterbalanced order. Merck sodium saccharin and commerclal cane sugar were used. Concentrations are expressed as percent of total weight of solution.

A few days after the completion of the 24-h measures, the short-term intake test was begun. The same procedure was followed, each $\mathrm{S}$ receiving either sucrose or saccharin as before, except that the solutions were removed after $30 \mathrm{~min}$. The testing was carried out at the same time each day.

Results

Figure 1 shows mean 24-h (A) and 30-min (B) ingestion for the two groups. Both sucrose and saccharin functions are arbitrarily superimposed on the same scale so that peak intake can be compared more readily. Except for an upward shift in preferred concentration from 24-h to 30-min intake of saccharin, the form of the functions is similar over long and short periods. Discussion

The most striking result is the difference in long-term intake of sucrose and saccharin. During 30 min about the same volume of both fluids were consumed, while during the 24-h period the peak saccharin intake is only about two-thirds that of the greatest sucrose intake. A simllar divergence was found previously, when only one concentration of sugar and saccharin were tested, and it had been concluded that the "initial" (i.e., first $30 \mathrm{~min}$ ) intake is specific to taste (LeMagnen, 1954; Smith \& Duffy, 1957). This interpretation must be ruled out, even for so short a period, for reasons discussed above. It is also contradicted by the immediate evidence, considering the intake across concentrations. The sweetest solution of sucrose is the one taken in the smallest volume, hence, more than taste is involved. It is probably only coincidental that shorter-term intake of both sucrose and saccharin fall at about the same level. The longer-term intake as well must be considered in the same light. The results may reflect the difference between a response governed by taste alone (saccharin) and a response governed by taste plus postingestion effects (sucrose). They cannot be taken to indicate a difference in taste only, or even a difference in nutritive value alone-a point of confusion in earlier work.

The question is still at issue whether the immediate reinforcing effect of saccharin and other noncaloric substances eventually extinguishes because it is not associated with reduction of hunger (e.g., Capretta, 1962, 

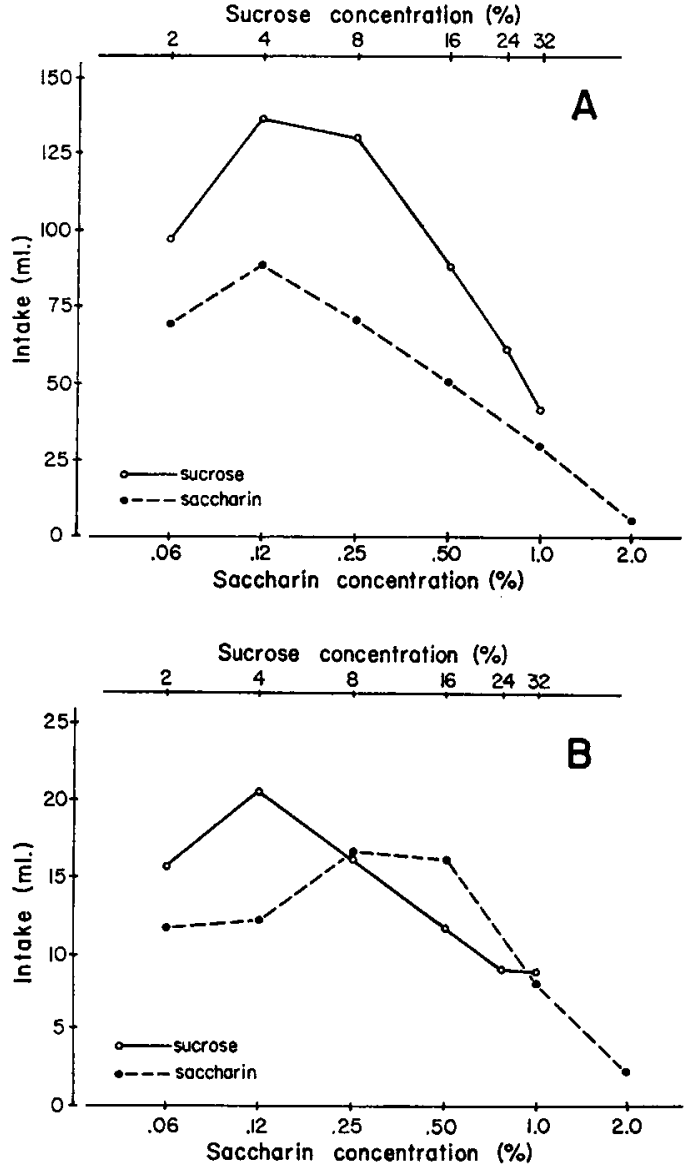

Fig. 1. (A) 24-h and (B) 30-min intake of sucrose and saccharin (note change in scale). Each point represents the mean of six animals.

1964). Unfortunately, treatment of this question, important as it is for any theory of reinforcement, has often confused the issue of immediate gustatory reinforcement per se with the separate issue of the metabolic regulation of intake.

The present data are not appropriate for drawing conclusions about the relative reinforcement values of saccharin and sucrose. However, if it is argued that only the satiating effects of sugar prevent a rat from drinking as much as it would like, then saccharin, or sham, intake should exceed that of sucrose. The data do suggest that, on the contrary, saccharin is much less preferred even at optimum concentration. This suggestion gains some validity from the direct taste preference tests of Young \& Madsen (1963). Their results showed that at best concentration $(0.4 \%)$ saccharin is equivalent in palatability to a relatively dilute solution of sucrose (about $4 \%$ ). In view of this appreciable dif- ference, it is a little surprising that saccharin should be regarded as so effective a reinforcer for instrumental behavior. Indeed, the decline in rate of bar pressing observed by Collier (1962) may be a result of just this low reinforcement value. Personal experience indicates that it is significantly harder to train rats to bar press with saccharin than with sugar reinforcement, although a direct comparison needs to be made. Because of the aversive, bitter quality that humans note in saccharin at $2 \%$ or even lower concentrations, it is plausible that the differences found in rats' acceptance of saccharin and sucrose are due simply to qualitative differences in taste.

In any case, the relatively low intake of saccharin over $24 \mathrm{~h}$ can hardly be viewed as extinction of saccharin drinking because it was not accompanied by hunger reduction. It could be said that the animal was not reinforced for returming to the saccharin bottle as often as to the sugar bottle because, from saccharin, he got only sensory satisfaction, but from sugar, both sensation and nutrition. On the other hand, the saccharin may have been a weaker reinforcer because its taste is less preferred than most of the range of sugar stimuli that were used. Either possibility raises questions of interpretation when need reduction is compared with sensory reinforcement.

\section{References}

Capretta, P. J. Saccharin consumption under varied conditions of hunger and drive. J. comp. physiol. Psychol., 1962, 55, 656-660.

Capretta, P. J. Saccharin consumption and the reinforcement issue. J. comp. physiol. Psychol., 1964, 57, 448-450.

Collier, G. Some properties of saccharin as a reinforcer. J. exp. Psychol., 1962, 64, 184-191.

Guttman, N. Equal reinforcement values for sucrose and glucose compared with equal sweetness values. J. comp. physiol. Psychol., 1954, 47, 358-361.

Hammer, L. R. An analysis of the reinforcement value of two sugars. Unpublished doctoral dissertation, Harvard University, 1965.

LeMagnen, J. Le processes de discrimination par le rat blanc des stimuli sucre alimentaires et non alimentaïres. J. Physiol., (Paris), 1954, 46, 414-418.

Mook, D. G. Oral and postingestional determinants of the intake of various solutions in rats with esophageal fistulas. $J$. comp. physiol. Psychol., 1963, 56, 645-659.

Sheffield, F. D., \& Roby, J. B. Reward value of a non-nutritive sweet taste. J. comp. physiol. Psychol., 1950, 43, 471-481.

Smith, M., \& Duffy, M. Consumption of sucrose and saccharin by hungry and satiated rats. J. comp. physiol. Psychol., 1957, 50, 65-69.

Young, P. T., \& Madsen, C. H., Jr. Individual isohedons in sucrose-sodium chloride and sucrose-saccharin gustatory areas. J. comp. physiol. Psychol., 1963, 56, 903-909.

\section{Note}

1. This research was carried out during the author's tenure as an NSF Predoctoral Fellow in the Department of Psychology, Harvard University. 